\title{
Enhancing A Holistic Wellness Among Female Students at a University in Eswatini Through Relevant Intervention Strategies for Support
}

\author{
Thandi F. Maziya $^{1} \quad$ Racheal Mafumbate $^{2^{*}}$ \\ 1.Southern Africa Nazarene University, Faculty of Education \\ 2. University of Eswatini, Department of Educational Foundations and Management, Faculty of Education
}

\begin{abstract}
The study sought to explore relevant intervention strategies for addressing academic, personal, social, and career needs for female students at a university in Eswatini with a view to enhance a holistic wellness of students. A qualitative approach using a single case study design was used to collect data from twenty-two students who were purposively selected from three faculties of this university including two counselors. Data were collected using focus group discussions and semi-structured interviews and analysed using thematic analysis. The findings revealed that female students needed intervention strategies such as guidance and counselling, robust orientation services, cultivation of harmonious interactions, spiritual support, and physical support in the university to address their needs. The study recommended that the university should match quantitative growth with qualitative support by enhancing holistic wellness of female students in the institution.
\end{abstract}

Keywords: wellness, female, strategy, Eswatini, students,

DOI: $10.7176 /$ RHSS/9-18-11

Publication date:September $30^{\text {th }} 2019$

\section{Orientation}

Female students have remained the fastest-growing segment in institutions of higher learning in most parts of the world today (Sue \& Sue, 2013; Essack, 2014). Provision of holistic wellness for female students is necessary not only for enhancing their academic performance in these institutions, but for developing their individual potentialities to the maximum possible extent so that, in line with the general philosophy of education, they live an effective and holistic life and contribute the best for the progress of society they live in (Nwite \& Nwuche, 2016). The focus of this study is on investigating the intervention strategies for enhancing holistic wellness for female students at a university in Eswatini.

Various legislative and humanitarian efforts of the international community have been channeled to improving the status of women in many areas that impact women lives. Education is one of these areas (Maqsood, Maqsood \& Raza, 2012; Essack, 2014). The First World Conference on Higher Education (FWCHE) through the 1998 World Declaration on Higher Education (WDHE) called for a major global effort to improve the delivery of higher education in every country in the world. In particular, WDHE notes that much more needs to be done to promote increased participation by women as one of the underrepresented groups of society. Female students have personal, social, academic, and vocational needs which they confront in day to day life situations (Oluremi, 2014; Abdul Azeez \& Sumangala, 2015; Jumana \& Meera, 2016). Such needs may interfere with the personal development and wellness of these students.

Wellness has been defined by Myers, Sweeney and Witmer (2010) as a way of life oriented towards optimal health and wellbeing in which body, mind and spirit are integrated by the individual to live more fully within the human and natural community. From this definition, any service that allows students to achieve optimal health can be considered an integral part in creating a healthy campus. A survey conducted by Calvarese (2015) to examine relationship between gender and reactions to stress among university students revealed more female students to be experiencing higher levels of depression, frustration, and anxiety than their counterparts. While several intervention strategies towards improving enrolment of women in institutions of higher learning such as Affirmative Action, lowering cut off points and remedial classes were instituted in African universities in the past (Bunyi, 2003), Peretomode and Ugbomeh (2013) describe enrolment in these institutions as a mere quantitative phenomenon without a corresponding qualitative support. According to Essack (2012) advocacy for matching equity of access to equity of outcome by successful participation and completion still calls for a number of pivotal, holistic and innovative strategies in post-student admission.

Eswatini Higher Education Council (EHEC) stipulates that institutions shall ensure that student support structures (medical, recreational, social and academic) are available to enable a conducive teaching and learning environment, and attainment of the programmes stated objectives (EHEC, 2015). Furthermore, Institutional Assessment Guideline (9) in the same framework requires that institutions should offer appropriate and adequate student support services, including, but not limited to, psychological, social, academic, and other needs (EHEC, 2015). Guidance and counselling in Eswatini operate under the name Educational, Testing, Guidance and 
Psychological Services Unit (ETGPS) and is one of the intervention strategies put in place by the Ministry of Education and Training in the country for ensuring the total development of an individual (ETGPS, 2003). According to Mkhatswa (2015) and Doran (2017), female students in Eswatini constitute a marginalized population inundated with barriers to education which are backed up by the patriarchal nature of the society. The focus of this study was therefore on exploring relevant strategies for enhancing a holistic wellness being among female students at a university in Eswatini through relevant support services.

Most studies conducted in Eswatini have concentrated on the provision of guidance and counselling support in primary and high schools (Magagula, 2004; Nhleko, 2006); Dlamini 2014). Mkhatswa (2015) asserts that a pervasive patriarchal ideology that essentializes women as inferior exists in Eswatini and pushes women to the periphery of decision making, exposing them to sexual abuse, poverty, and HIV infection. Since institutions of higher learning just like schools are a microcosm of the society they serve, not only exploring the needs that female students have in the face of such challenges is necessary, but soliciting relevant and effective intervention strategies for addressing these needs as well. Without relevant and effective strategies in place holistic wellness for female students may be very hard to achieve. From a perusal of the existing studies, the researchers established that studies specifically addressing guidance and counselling needs for female students and intervention strategies needed for enhancing these students' wellness are scarce. Magagula (2014) on examining constraints experienced by Adult Education Programme learners in the Kwaluseni campus of the University of Eswatini through a mixed method design, established that these learners experienced dispositional, situational, and institutional constraints without soliciting intervention strategies for addressing these constraints. Soliciting not only needs, but also intervention strategies that female students need for addressing these needs at a university is crucial not only for the enhancement of a holistic wellness for these students in order for them to develop their individual potentialities to the maximum possible extent, but also for them to live an effective and holistic life and contribute the best for the progress of society they live in. The focus of this study was thus on investigating the intervention strategies for enhancing holistic wellness for female students at a university in Eswatini.

\section{Theoretical framework}

This study used Hettler's (1984) wellness model as a theoretical framework. This model postulates that there are six different dimensions of human wellness which need to be fulfilled if a student is to fully experience learning and development that is positive, healthy, and complex. These dimensions are: occupational, emotional, social, intellectual, spiritual, and physical. Each dimension requires a deliberate personal commitment and time to reach an optimum level necessary for balance (Myers and Sweeney (2008) and a student must achieve between each of these six dimensions. Hettler (1984) proposes that students cannot develop psychosocially and intellectually without wellness.

Emotional wellness is representative of the awareness, understanding and management of one's feelings and behaviours related to things such as the ability to experience and express the full range of human emotions in appropriate ways including stress and relationship management. Emotional wellness includes experiencing satisfaction, curiosity, and enjoyment in life, as well as having a positive anticipation of the future, or optimistic outlook (Hettler, 1984). College brings a host of new demands and challenges (Conley, Travers, \& Bryant, 2013; Ulusoy,Varlikli, Dag, Sahranc \& Turan, 2014) and elevations in psychosocial distress manifest even more in female students than their male counterparts (Amr, El Gilany \& El-Hawary, 2008; Calvarese, 2015). Mafumbate (2012) concurs that this dimension is important in that it hinges on one's ability to cope effectively with stress.

In America, Swingle (2013) established that financial stress has serious impact among student mothers. The impact of financial difficulties, among other factors, was found to depend on marital status and emotional state of these mothers (Swingle, 2013). Also, Mutangi and Kashora (2015) found that single parent students raised money by alternate means, either from boyfriends or secretly from relatives to keep up with their financial responsibilities. Sometimes even negative coping strategies in the form of engaging in sexual activities to just go against the norm may be used by female students (Persaud \& Persaud, 2015). Similarly, a married woman student and a mother, may have challenges pertaining to the home (Lee \& Myers, 2005). A married woman student who has children often gets up very early in the morning trying to get everything done at home before going to lectures becomes tired and not very alert at classes ( Chigona \& Chetty, 2007). Quartey (2003) also asserts that as a result of the strains on their time and energy, married women experience fatigue, lack of time for revision and rest and have feelings of guilt over not fulfilling their traditional role expectations at home. Furthermore, Lee and Myers (2005) state that family problems create imbalance for married women students who are day-students or non-residential student because the husband always threaten to divorce the student woman as a result of poor marital performance and overweening behavior. This may result in depression, making her emotional state so fragile. Such a student is distracted and has divided attention at home and at academic work (Chigona \& Chetty, 2007). In a study carried out in South Africa, Kaufman (2001) found that mothers' adjustment to school life after giving birth during the program is not easy. According to their finding 
such mothers become divided between childcare and studies. However, when an individual is equipped in this dimension, the individual will have the ability to motivate oneself and persist in the face of frustrations (Mafumbate, 2012).

Social wellness is about the degree, content of interactions with others, the community, and nature. It also involves the extent of work towards supporting the community and environment actions, such as volunteer work (Hettler, 1980). It encourages contributing to one's environment and community through involvement in preserving societal and natural environment stability. It encompasses the quality of our relationships, satisfaction in our sense of belonging, and feelings of love and acceptance. Getting along with others and being comfortable and willing to express one's feelings, needs, and opinions; supportive, fulfilling relationships (including sexual relations), and intimacy are all embraced in the definition of social wellness (Long, 2012).

Institutional challenges which have to do with the institutions' administration system are some obstacles that female students face. Listed under this category are admission policies, registration procedures, disciplinary rules and policies as well as availability and quality of student support services and facilities (Othman, 2016). Wilks (2008) found that positive interactions between students and lecturers produce a conducive learning environment which can increase student motivation. Comparatively, conflict with unpleasant lecturers was found to increased student stress while good social support and team work lessened stress. Similarly, unpleasant classmates were found to produce or increase stress (Wilks, 2008). Moreover, social wellness for female students could also be offset by needs arising from extra roles and responsibilities as well as inflexible socio-cultural norms. Men and women usually accept the roles defined and perpetuated by their community which can have both advantages and disadvantages for them.

Moreau and Kerner (2012) noticed little or lack of institutional support on campus for mothers. Lectures are re-scheduled in the evening or into the night at the time day-care or other childcare service providers have closed. This made childcare a problem. According to Moreau \& Kerner (2012), academic programmes disregard the need of women during pregnancy, childbirth, and maternity leave. Ignoring this creates an atmosphere of condemnation hence student-mothers feel their issue has not been given attention. Student mothers suffer stress from both conflicting demands between family and academic work and motherhood (Oswalt \& Riddock, 2007; Bitsika et al, 2010; Amos \& Manieson, 2015). For example, childbearing and nursing time, and pregnancy means the progress of academic work is stopped or slowed down (Moreau \& Kerner, 2012). While mothers without nursing babies could spend nights in the library researching, nursing mothers without reliable childcare facilities cannot do that (Springer et al., 2009). This leaves such students emotionally drained and requiring effective counseling and guidance to ensure they pull through their studies.

Springer, Parker \& Leviten-Reid (2009) also noted that mothering is not normative on campus. Student mothers experience awkward pauses rendered by pregnant bodies on campus, struggle to navigate strollers in classrooms, and search to find clean and discreet places to feed their babies. Although sometimes subtle, there are constant reminders in the social and physical environment of the university that student parents and their children do not truly belong (Springer et al., 2009). The reality is that it is not the fault of female students that they are mothers, however society expect them to be the ones to take care of the babies at all costs. This may be because from childhood, women are socialized to be more caring towards others as well as to highly value the development of interpersonal relationships hence it is easier for them to express their needs with others compared to men who are socialized to focus more on competition, independence, and inhibiting emotional expression (Krause, Ellison, \& Marcum Mirola, 2002).

Intellectual wellness, involves 'stimulating the mind for stimulation sake; keeping one engaged in meaningful, informed conversation on an ongoing basis' (Hettler, 1984). Intellectual wellness requires curiosity and a strong desire to learn, solving problems, thinking independently, creatively and critically (Adebayo, 2013). So, this dimension meshes together the state of one's knowledge, skills and creativity for problem solving and teaching (Adebayo, 2013). According to Hettler (1984), intellectual wellness represents a commitment to lifelong learning, an effort to share knowledge with others, and development of skills and abilities to achieve a more satisfying life (Long, 2012).

The intellectual dimension informs support for female university students in that according to some researchers, females feel less confident than males in pursuing university courses (Hancock, Davies \& McGrenere, 2002; Wilson, 2002). A study by Stoilescu and McDougall (2011) specifically explored factors that alienate undergraduate female students and exacerbate gender disparities in confidence, performance, attitudes, and experience in undergraduate education. Women can face unique barriers that include negative stereotypes, negative influences and discrimination. In the past women have been faced with a lack of role models, lack of encouragement and insufficient opportunities to succeed in the areas of Maths and Science (Cordero, Porter, Israel \& Brown, 2010). Several reasons have been postulated in the literature and include real and perceived challenges associated with balancing work and family life (Alpay, Hari, Kambouri \& Ahearn 2010). There is growing literature that men are more confident than women in exam situations (Bengtsson, Persson \& Willenhag, 2005). 
Students who repeatedly underestimate their performance can lose motivation for learning, due to a lack of self-confidence. Similarly students who over estimate their performance may be at a disadvantage as their over confidence may impede their motivation to learn new techniques (Stankov, Morony \& Lee, 2014). It is clear that self-confidence is required to enhance the academic progress of students and it is more especially important in an environment where women are culturally viewed as inferior. It is the role of guidance and counselling in a tertiary institution to formulate programmes that can boost the self-confidence of female students and increase self-esteem which would ultimately lead to better academic progress.

The occupational wellness dimension is founded on the principle of personal satisfaction and enrichment of life through work. Meaningful work which requires development is correlated to attitude and personal choice. Choosing a career which is consistent with one's personal values, interests, and beliefs as opposed to selecting a career that is unrewarding is encouraged, and so is developing functional, transferable skills through structured involvement opportunities than remaining inactive and uninvolved (Hettler, 1984).

Niles and Harris-Bowlsbey (2005) opined that women constitute the majority of students enrolled in higher education and they present with career development needs that are considerably different than those of males. Furthermore, career imbalance on marital fronts of the African culture has been traced to the background patriarchy that underpins almost everything on the continent (Hammer, Grigsby \& Woods, 1998). Career stereotyping is another concern in the education of female students. Social experience has been shown to impede persistence in Science, Technology, Engineering, and Mathematics (STEM) majors among female students (Gayles, 2014; Thamarasseri, 2014). Musingafi and Mafumbate (2014) observe that prolonged and deep seated marginalization of women in the African society may sometimes even render efforts at remedying imposed stereotypes counterproductive.

On reviewing the provision of guidance and counselling in Camerron, Bobga (2016) came to the conclusion that guidance and counselling posed as an intervention strategy which is a transformer, reformer in educational and socio personal practices in every society while Nwite and Nwuche (2016) view it as a lubricant for the teaching-learning machinery that may benefit female students even more than their male counterparts (Rascon, 2012. Bobga (2016) further identifies the orientation programme, Occupational Information Services, and Follow-up services as vital components of an effective guidance and counselling programme. Frazer (2014) asserts that an effective orientation programme has to have a career-based workshop which is critical to student success, retention, and persistence. This career workshop should outline career-specific and programme-based employability skills, as well as information about industry and job market (Frazer, 2014). Furthermore, this career component ensures that all students in all programmes are exposed to a common motivational and educational foundation and the information.

Spiritual wellness embodies the beliefs and attitudes towards nature and the meaning-making an individual undertakes to identify what has ultimate value to them (Ford, 2015). It is evident in the search for understanding of how life is, or ought to be and thus the choice of direction and resulting feelings of life's purpose. Spiritual wellness is focused on harmony with the self, and with others and the universe, and the search for a universal value system (Hettler, 1984).

Anderson (2015) postulates that spiritual wellness is 'the sweet spot for wellness and lying at the intersection of the body, mind, and spirit' and therefore it is the 'lifeblood of campuses'. If spiritual needs are not met or nurtured they translate into negative emotions and deplete a student's energy (Linda, Klopper, \& Phetlhu, 2015). Furthermore, Krause, Ellison, and Marcum (2002) indicated that women may receive more benefit from religious and spiritual involvement than men do and such benefit may include more social support. Mutangi and Kashora concur that this dimension is vital in student support due to its role in reducing the risk of distress in female students following adverse life events. Furthermore, El-Islam (2015) submits that religion or spirituality helps to provide a meaning for stress and instills hope in relief of the ensuing distress.

Physical wellness can be referred to as the willingness to pursue an active lifestyle (Myers \& Sweeney, 2005). It encompasses the need for physical activity, understanding of diet and nutrition, discouragement of the use of harmful substances and personal responsibility for medical and self-care. It also involves personal responsibility and care for minor illnesses and knowing when professional medical attention is needed as well as understanding and appreciating the relationship between sound nutrition and how the body performs (Khan, Rehman, Baig, Hussan, Khan \& Syed, 2015). D’Abundo (2009) interpolate that physical wellness includes the ability of the body to function effectively and meet the demands of daily life. This includes cardiovascular endurance, strength and flexibility in addition to healthy nutrition, sound medical care, and personal safety (D’Abundo, 2009). Also, issues of sleep quantity, sleep quality, sleep regularity are important.

The dimension of physical wellness has the ability to impact the other dimensions of wellness (Conley, Travers, \& Bryan, 2013). For instance, exercise has numerous benefits for students, including increased academic performance, decreased stress, improved mental health, and overall health (Hattie, Myers \& Sweeney, 2004). According to Anbumalar et al., (2017) when stress occurs, the human body prepares for a quick action by releasing hormones that increase alertness and focus. However, if the source of stress does not disappear, stress 
hormones can persist in the body and continual exposure to stress hormones has been linked to a wide range of physical illnesses in female students such as obesity, gastrointestinal disorders, cardiovascular disorders, skin disorders, anxiety attacks, and depression (Bitsika, Sharpley, \& Melhem, 2010; Anbumalar, Dorathy, Jaswati, Priya, \& Renlangelin, 2017). Furthermore, Siddiqui and Aziz (2012) concur that when stress becomes excessive, it leads to various diseases and tensions, and can consume the student's attention and energy resulting not only in lower academic performance, but relationship dilemmas, depression, and even death. Also, due to multiple roles and responsibilities, female students may lack time and energy for engaging in activities that enhance physical wellness (Bitsika et al., 2010).

\section{Materials and methods}

To satisfy the objectives of the study a qualitative approach to research was followed. The study was confined to the guidance and counselling needs facing female students in one specific university. The study employed purposive sampling method in selecting participants. The sample for this study was a total of 24 participants comprising of 22 female students and 2 counsellors from Faculty A. The study used semi-structured interviews and focus group discussions (FGDs) to collect data from the female student participating in the study. The individual interview were administered to the two counselors who participated in the study.

\section{Results and discussion}

Results of the study revealed intervention strategies needed by female students to be the provision of professional guidance and counselling; provision of robust orientation services; cultivation of harmonious interactions; spiritual support; and physical support.

The need for professional guidance and counselling support from qualified counselor emerged as a need for female students in the study. The study revealed that female students in the university were in need of professional guidance and counselling, and this need was shared by participants in all the three faculties as reflected in the data excerpts presented below: "I think the institution should hire someone specifically for counselling and guidance and not teaching, just counselling and guidance. If you have a problem, you know where to find that person and there should be a confidentiality clause there because. if it's a lecturer, the lecturer will make an example with it in class as it is the case right now" (Participant \# 4, Faculty A, FGDs).

In a separate interview, the same perception was shared by another participant in the following voice: "I think counselling can help. The university needs to hire somebody so that when I come from home stressed and having all the problems he or she can take keys to the office and I can talk to him /her. I think it helps to have somebody to talk to because you get healed. Even if he / she cannot help you that much, the fact that you have a shoulder to cry on makes a difference” (Participant \# 9, Faculty A, FGDs).

Echoing the words of the previous participant, another participant in another faculty had this to say: "To address our stress and anxiety, we don't have anyone. Usually, other universities have students' psychologists that you see if you feel like you are not coping. So we don't have it here. Actually that would be of great help, just being able to vent to someone “... (Participant \# 2, Faculty C, FGDs).

Findings of the study revealed that female students in the university needed provision of professional guidance and counselling for addressing the academic, personal, social, and career needs they were experiencing in their education. Participants revealed that they needed to be afforded academic counselling to equip them with confidence in their education so as to withstand the oppressive socio-cultural stereotypes that hinder their academic, social, and career success and wellness. Also, participants needed counselling services for addressing the psychological distress which came with the multiple roles and responsibilities in their lives as female students.

The study also revealed that female students yearned for adequately and efficiently organised orientation programme for students in the university. The career component of this programme, which is mainly concerned with career education, was found not to fulfill the needs for female students. Such a view was mainly expressed by participants from Faculty $\mathrm{C}$ who voiced a need for a robust orientation programme to be put in place for their benefit as female students. For instance, responding to a question on how female students' career needs could be supported at the university, Participant 2 had this to say: "I think this thing gets left off with orientation because when they're orienting us here all they talk about is AIDS prevention and pregnancy prevention, which is not what I came here for" (Participant \# 2, Factulty C, Semi-structured interviews).

The same opinion was shared by another participant in the same faculty like this: "...fine you had applied for the course which you think is best for you but when you get here orientation day, you come thinking its orientation but it is not. It is just like they call so many people to come and advertise to you. Like the banks, they come here to promote their own stuff in the institution, but they do not promote the course, because there are different courses that are being offered. Also, orientation, according to me, I think it should be organized per course" (Participant \# 1, Faculty C, FGDs).

In the same faculty, Participant 2 echoed the same need in the semi-structured interview like this: “... I think 
orientation should be done per course, if it is not done per course, if we are all there, then there should be different specialist on each course, who will educate us that if you joining this course, this is the interesting part, this is the bad side, all the pros and cons we should be told. To really motivate you, that you have chosen the best course as a female student... that's something the institution lacks on" (Participant \# 2, Faculty C, Semistructured interviews).

Participants expressed need for them to be afforded relevant orientation on admission to the institution. In particular, participants from Faculty $\mathrm{C}$ in the Pharmacy course decried the orientation they received on admission to the institution hence relevant information support was lacking. Participants further revealed that the orientation programme organized by the university for them was one sided with information about HIV prevention and pregnancy, and banks advertising their stuff while career guidance was lacking. Furthermore, participants wanted to be informed on various paths available to them after graduation and voiced a need to have faculty members and course tutors advertise different courses to them as a way of motivating them. On the other hand, Faculty B preferred orientation services for the enhancement of social integration and saw the services as means of getting them to know one another. Faculty A revealed main concern about setting of aspirations in accordance with individual abilities and interests and decried being forced into course streams they lacked these in.

The study also established that female students needed harmonious interpersonal relationships to exist in the university. A student-friendly school environment that enhanced the social wellness of these students was expressed as possible to attain through student-friendly rules and policies and harmonious interactions in the institution as illustrated in the data excerpts presented under this subtopic.

Pertaining student-friendly rules and policies, findings of the study revealed that female students wished for the university to consider issuing or formulating policies and rules that were going to accommodate their special needs as women. Such needs arise from the multiple roles and responsibilities they had as female students. One married expectant mother had this to say: "Another issue is that they should understand that we are old enough and must allow us to be pregnant. If I'm pregnant it does not mean that I have to hide everywhere I go. I'm not at high school now. So they must allow us to be pregnant" (Participant 4, Faculty A, FGDs).

Another participant voiced her displeasure at some of the rules that lecturers made concerning late coming to class in disregard of the many roles and responsibilities she had to contend with as a single mother and part time employee. She shared: "Sometimes they (lecturers) would even shut you out of the class when you are even five minutes late and tell you straight in the eye that, "once I get into class, no one comes after me" (Participant \# 3, Faculty C. FGDs).

The study also revealed unfavourable rules around issues of hairstyles and make-up to exist in some faculties as reflected in the following excerpt: "... What has the lipstick got to do with my school work because this is what I like? Even the weave and hairstyles, "... So now I have to plait cornrows...yet if I feel like putting on anything I want... I can just do... this is a university-it's not a high school, if I feel like putting on my makeup or weave... allow me to do that" (Student \# 8, Faculty A, FGDs).

Apart from rules and policies, the study also revealed discriminatory treatment of students on the basis of the programmes of study they were in. The study alluded to some students getting preferential treatment than others which disrupted and crippled healthy interactions among these students as revealed in the excerpt below: "The university has to accommodate everyone, not just nurses. It's like sincikile kubo nurse "we are squatters on the nurses' camp". Everything is about them. They (faculty administration) just don't care about our needs - they just don't care. I think they have to equalize" (Participant \# 6, Faculty C, FGDs).

Furthermore, another participant from Faculty $\mathrm{C}$ echoed the same disharmony, this time between students and lecturers in the following voice: "If they (female lecturers) can be friendly towards us- treat us as their children and not bring their frustrations from home to the university" (Participant \# 3, Faculty A, FGDs).

On spiritual wellness support provision in the university, the study found participants to express varying degrees of satisfaction. Provision of spiritual support was availed to students in all three faculties of the university. However, such provision was expressed as exceptionally adequate and relevant by participants from Faculty A, while participants from the other two revealed dissatisfaction in the spiritual support provided for them in the respective faculties. Participants felt the spiritual services rendered did not speak to their needs due to different factors related to the manner in which such support was rendered in these faculties. In Faculty B, for instance, participants voiced a need for well and effectively rendered sermons for spiritual upliftment. Participant 2 who was also involved in sharing the word of God to her fellow students had this to say: "In our university we have devotions and chapel, but sometimes it comes to a point whereby it is not helpful. It's not really meeting our needs... the way our sermons are structured is not working...you find that in a semester we do one and the same theme; which is boring" (Participant \#2, Faculty B, FGDs).

Participant 1, from a different programme of study in the same faculty, who formed part of the recipients of these sermons echoed the same sentiment as the previous participant in the following voice: "It's really boring for us students because we don't understand what they are doing they will come and do introduction, like tell us 
this was written by so and so, someone I don't know and I ask myself," How does that concern me" ... (and) you find that the person is busy shivering and speaking in broken English there, and we will be asking each other," what is he /she saying?'. They become a laughing stock and they too get disturbed... and they cannot hear anything they are saying" (Participant \# 1, Faculty B, FGDs).

Furthermore, the medium of preaching, which is the English language was cited as another barrier by another participant. The participant shared: "Also the language we use for preaching restricts our expression and the way God wants to use us because while we are preaching, the lecturers are marking us grammar" (Participant \# 3, Faculty C, FGDs).

Participant 3 then had to share the following as a remedy for ineffective spiritual support in the faculty: "...we want this place (chapel) not to be used for training. Presentations and training must be done in class and when we come to this place, no red pens, no comments or what. We must worship God freely. I should be able to express myself in SiSwati or English if I want. I must feel free to do what God has called me to do" (Participant 3 , Faculty C, Semi-structured interview).

While the need for spiritual support was also expressed in Faculty B, the reason for dissatisfaction with such support seemed to be different. Participants alluded to lack of faith or conviction in such support as a major contributory factor to their dissatisfaction. One of the participants had this to say: That's the only thing they know because in the morning we pray, on Wednesdays we have a service, and then Fridays there are night prayers. They do not lack on that one"," (Participant \# 5, Faculty C, FGDs).

When probed further to say if these services do work for her she hesitantly replied: "It works. Yes...but at times you feel like- no! This thing needs me to be practical than spiritual. It needs me to do it manually. It needs you giving me money to go cover that other thing and not tell me, " receive! Receive!" (Participant \# 5, Faculty $\mathrm{C}$, FGDs).

Need of support for female students physical wellness was found to exist in the university. Participants from all the three faculties of the university expressed that the physical dimension of wellness was not adequately supported in the university. Participants cited lack of proper planning, inadequate sporting activities and lack of proper diet to be prevalent in the university. The university was found to be disorganized regarding the planning of sports and social events for female students were not available. "There's no netball team (and) there's no sport field...we don't get a chance to train or we don't even have a simple gym...the school (university) doesn't provide us with a chance to distress with sports. As for me personally, I really need the aerobics and training, but the school does not provide that" (Participant \# 1, Faculty C, semi-structured interview).

Discriminated provision of spiritual support in this faculty was also alluded to by the participant in the following excerpt: "...I cannot participate in the games that they have... the sports are available but I cannot just go there and make fun out of myself (because) it's for nurses"... (Participant \# 2, Faculty C, semi-structured interviews).

Also, lack of equipment and facilitators for some of the sporting activities was cited as contributory factors to the experiences of need in this area as illustrated in the following excerpt: "...they have volleyball and tennis courts, but we come from villages...there are no facilitators to teach us these other sports. Sometimes there is no equipment, you find that there is only the table" (Participant \# 5, Faculty B, FGDs).

Furthermore, findings of the study indicated that female students needed the university to provide personal health care, in particular reproductive health care on campus hence they would not have to miss lectures each time they need such services. "I think the institution has to structure some sort of health related clinic or something... as females we go through a lot. It's not only the pregnancy issues, also other issues that involve the female reproductive system ... we are supposed to have at least a nurse or a smaller pharmacy”... (Participant 1, Faculty C, semi-structured interview).

The need for provision of proper food was also expressed by participants in Faculty A as illustrated in the excerpt below: "...I feel like may be the university must give us food...but I feel like maybe they must give us proper food than they used to give us in the past”... (Participant \# 1, Faculty A, semi-structured interview).

In the above excerpts, the need for physical support was also revealed as another need for female students in the university. Findings of the study revealed that sporting activities were ill organized and limited in terms of variety. Faculty B reported lack of equipment and qualified sports personnel to man the department. Participants from Faculty $\mathrm{C}$ reported a total lack of physical support and cited discrimination tendencies in the institution when it comes to this while need for provision of proper meals on campus for students was indicated in the study in faculty A.

\section{Conclusion and recommendations}

From the findings, it can be concluded that female students in the university desired to have holistic intervention approach to the personal, academic, social and career needs they experienced in the university. While these students desired professional guidance and counselling intervention to be adopted in the university, they also 
expressed a need for other intervention strategies such as robust orientation programme, spiritual support, and physical support. Female students needed the aforementioned intervention strategies not only for circumventing the negative emotions and experiences in these dimensions, but also for them to live more fully within the human and natural community and also contribute to the socio-economic development of the country as alluded to in the African proverb "If you educate a man, you educate an individual, but if you educate a woman you educate a family and nation".

The study made the following recommendations for action:

- A professional guidance and counselling unit should be put in place in the Student Affairs Department for addressing and preventing emotional and psychological problems which emanate from academic, social, personal, and career related issues among the students in the university.

- Guidance and counselling be manned by professional counsellors who should not be dually engaged as educator-counsellors, but be engaged solely as counsellors for the students.

- The university adopts a more vigorous orientation exercise that will incorporate various strategies and / or resources and programmes geared towards orienting and inducting female students effectively to facilitate not only transition from high school, but to enable successful navigation of and integration into the university as well as helping students understand various trajectories of their career development.

- The Ministry of Education and Training (MoET) should invest in the training of more professional guidance and counselling personnel to work with students in the country's universities.

\section{References}

Amani, J., \& Sima, R. (2015). The status of career services in higher learning institutions in Tanzania. International Journal of Education and Social Science, 2 (8), 265- 283.

Anderson, L. S. (2015). Predictors of parenting stress in adverse sample of parents of early adolescents in highrisk communities. Nursing Research, 57 (5), 340 - 350.

Anbumalar, C., Dorathy, A. P., Jaswanti, V. P., Priya, D. \& Renlangelin (2017). Gender differences in perceived stress levels and coping strategies. International Journal of Psychiatry, 26 (4), 78 -98.

Anyi, E. M. E. (2017). The role of guidance and counselling in effective teaching and learning in schools: The Cameroonian perspective. International Journal of Educational Technology and Learning, 1, (1), 11-15.

Assoah, S. K. (2019). Personal needs as correlates of life skills needs of first year students at College of Technology Education, Kumasi. European Journal of Training and Development Studies, 6, (1), 1-12).

Bengtsson, C., Persson, M. \& Willenhag, P. (2005). Gender and overconfidence. Economics Letters, 86 (2), 199 203.

Bobga, T. J. (2016). An appraisal of effective provision of guidance and counselling services in Cameroon State University: Trends and challenges. International Journal of Humanities Social Sciences and Education, 3 (9), 75-90.

Bunyi, G. W. (2003). Interventions that increase enrolment of women in African tertiary institutions: A Case study prepared for Regional Training Conference on Improving Tertiary Education in Sub-Saharan Africa. Accra.

Calvarese, M. (2015). The effects of gender on stress factors: An exploratory study among university students. Social Sciences, 4, 1177-1884.

Chigona, A. \& Chetty, R. (2007). Girls' Education in South Africa: Special Consideration to Teen Mothers as Learners, Journal of Education for International Development,3(1).

Cordero, E., Porter, S., Israel, T. \& Brown, M. (2010). Math and science pursuits: A self-efficacy intervention comparison study. Journal of Career Assessment, 18(4), 362-375.

Conley, C. S., Travers, L. V., Bryan, F. B., (2013). Promoting Psychological adjustment and stress management in first- year college students: The benefits of engagement in a psychological wellness seminar. Journal of American College Health, 61 (2).

D’Abundo, M. L., (2009). Health, aesthetics and physical activity in aerobic classes for women. Sports, Education and Society, 6 (3), $301-319$.

Doran, G. (2017). The barriers and current state of female education in Swaziland.

Global Education.

El-Islam, M. F. (2015). Religion and Mental Health. The Arab Journal of Psychiatry, 326 (1), 1-3.

Essack, S. Y. (2012). Translating equitable access into retention and success in African higher education: The role and responsibility of individual institutions. Journal of Higher Education in Africa, 10, (2), 47-62.

Frazer, L. (2014). Making your mark. National Institute for Staff and Organizational Development, 4, (9) 4717545.

Gayles, J. G. (2014). The impact of college experience on degree completion in STEM fields at four-year institutions: Does gender matter? The Journal of Higher Education, 85 (4), 439-468. 
Hammer, L. B., Grisby, T. D., \& Woods, S. (1998). The conflicting demands of work, family, and schooling among students at an urban university. The journal of Psychology: Interdisciplinary and Applied, 132, (2), $220-226$

Jumana, M. K., \& Meera, K. P. (2016). Present day need for guidance and counselling among graduate students. International Journal of Applied Research, 2 (6), 553-555.

Khan, R., Rehman, R., Baig, M., Hussain, M., Khan, M., \& Syed, F. (2015). Dimensions of physical wellness among medical students of public and private medical college in Pakistan. Saud Medical Journal, 36 (6), $754-758$.

Krause, N., Ellisson, C. G., \& Marcum, J. P. (2002). The effects of church-based emotional support on health: Do they vary by gender? Sociology of Religion, 63 (1), 21-47.

Lee, T. \& Myers, W., (2005). Modern Woman student and family problems. McMillan Publishing Company: New York.

Linda, N. S., Klopper, H. C., \& Phetlhu, D. R. (2015). Students' voices on spiritual care at a higher education institution in Western Cape. Curationis 38, (2).

Mafumbate, R. (2012). The involvement of extended families in the wellness of orphans in a primary school in Masvingo City, Zimbabwe. PhD. [Unpublished]: University of Johannesburg. Retrieved from: https://ujgispace.uj.ac.za (Accessed 13/05/18)

Magagula, T. K. (2014). Constraints experienced by learners participating in Adult

Education programmes: Implications for guidance and counselling services at the University of Swaziland (UNISWA) Kwaluseni campus. Unpublished master's thesis, University of Swaziland, Swaziland.

Maqsood, F., Maqsood, S., Raza, H. (2012). Getting higher education: Is it really a challenge for females in Pakistan? Academic Research International, 2 (3), 352-360.

Miller, J. J. (2011). Impact of a university recreation center on social belonging and student retention. Recreactional Sports Journal, 35, 117-129.

Mkhatswa, T. P., (2015). Written narratives as an avenue for Swazi women to debate marginalization and inconsistencies of Patriarchy. Master's Thesis. Urbana, Illinois.

Moreau, M-P. \& Kerner, C. (2012). Supporting Student Parents in Higher Education: A policy analysis. http://www.nuffieldfoundation.org. (Accessed on 23/02/2019).

Morghadam, Z.B., Khlaban, M.O., Esmaeli, M. \& Salsali, M. (2017). Motherhood challenges and well-being along with the studentship role among Iranian women: A qualitative study. International Journal of Qualitative Studies on Health and Well-being, 12 (1) 1748-2631.

Musingafi, M.C.C., \& Mafumbate, R. (2014). Students' perception of girlchild affirmative action in high schools in Masvingo Urban, Zimbabwe. International Journal of Education and Practice, 2, (9), 192-212.

Mutangi, E. S. \& Kashona, P. (2012). Obligations, challenges, and coping mechanisms for women in tertiary education: A case study of women's university in Africa. International Journal of Humanities and Social Science, 2 (15).

Myers, J. E., Sweeney, T. J. (2005). Wellness counselling: The evidence base for practice. Journal of Counselling and Development, 78, 251- 266.

Niles, S. G., \& Harris-Bowsbey, J. (2005). Career development interventions in the $21^{\text {st }}$ Century. ( $2^{\text {nd }}$ ed). Columbia: Pearson.

Nwite, O. \& Nwuche, R. A. (2016). Evaluation of students' personal services in colleges of education in Nigeria. British Journal of Education, 4 (7), 82-98.

Orulemi, F. D. (2014). Functional guidance and counselling centre in tertiary institutions. Journal of International Social Research, 7 (31).

Oswalt, S. B., \& Riddock, C.C., (2007). What to do about being overwhelmed. College Student Affairs Journal, 27 (1) 24-44.

Othman, A. (2014). A review of the contemporary international literature on student retention in higher education. International Journal of Education \& Literacy Studies, 4(1)

Quartey, D., (2003). Married student and traditional role in Ghana. Mayfield Publishers, Accra.

Siddiqui, A.F., Aziz, S.A. (2012). A comparative study of the private and public sector medical colleges in Karachi with reference to quality of education. Interdisciplinary Journal of Contemporary Research in Business, 3, 526 - 534.

Springer, K. W., Parker, B. K. \& Leviten-Reid, C. (2009). Making space for graduate student parents: Practices and policies. Journal of Family Issues, 30, 435-457.

Stankov, L., Morony, S. \& Lee, Y. P. (2014). Confidence: The best non-cognitive predictor of academic achievement? Educational Psychology, 34(1), 9-28.

Stoilescu, D. \& McDougall, D. (2011). Gender digital divide and challenges in undergraduate computer science programs. Canadian Journal of Education/Revue canadienne de l'éducation, 34 (1), 308-333.

Sue, D. W. and Sue, D. (2013). Counselling the culturally diverse: Theory and practice. (6 ${ }^{\text {th }}$ ed.) New York, NY: 
Wiley.

Thamarasseri, I. (2014). Meta-narrative on guidance and counselling in schools. Central University of Kashmir. India.

Ulusoy, Y., Varlikli, G., Dag, F., Sahranc, U. and Turan, H. (2014). Determination of the needs of university students for psychological counselling and guidance services: The case of Koceli University. Turkey. Educational Research and Reviews, 9 (10). 286-293.

Wilks, S. E. (2008). Resilience and academic stress: The moderating impact of social support among social work students. Advances in Social Work, 9 (2), $106-125$. 